of these simple experiments the inference is that sugar is absent from strictly normal urine.

There are doubtless cases in which a trace of sugar may, for a time, be found in the urine of apparently healthy persons, as a result of an excess of saccharine and farinaceous food, or a defective power of assimilation; so there are cases of temporary albuminuria consequent on prolonged cold bathing, over-fatigue, alcoholism, mental worry, or a fit of indigestion, but glycosuria and albuminuria are alike abnormal, and not physiological.

The rarity or the frequency of a trace of sugar in the urine of the apparently healthy will be the more easily ascertained now that we have a simple and certain method for its detection.

Savile-row, July 31st, 1894. I am, Sirs, yours faithfally, GEORGE JOHNSON.

\section{"FAILURE OF A VESTRY PROSECUTION FOR NON-NOTIFICATION."}

To the Editors of THE LANCET.

SIRs, - With reference to your annotation last week under the above title, the vestry failed in their prosecution because within an hour of my finding that three children were suffering from diphtheria I sent my notification direct to the medical officer of health, or, in his absence from the vestry, the sanitary inspector, I wrote the notification on one "form " and directed Sister Louisa the way to the vestry from my house. It so happened that she had to pass the Orphanage, and she went in. The Sister in charge had meantime resolved not to send the children to the hospital. The Sister's mission to the vestry was a double one: (1) to deliver my notification certificate, and (2) to ask the medical officer of health to order the removal of the children to the hospital. In the extreme agitation the Sisters confused my notification with an "order" to have the children removed to the hospital. I am, Sirs, yours traly,

WILLIAM FEARNLEY.

Elgin-avenue, Maida-vale, W., Aug. 4th, 1894.

\section{THE REPORT ON THE HEALTH OF LIVERPOOL IN 1893: A PROTEST. \\ To the Editors of THE LANCET.}

SIRs,-Permit me to call your attention to the treatment I have experienced from the Health Committee of this city and their newly-appointed medical officer. In accordance with the regulations of the Local Government Board, I presented to the Health Committee, on the 22nd of last March, my report on the health of Liverpool during the year 1893. The committee passed a resolution that it was to be printed, as on former occasions, and when I retired from my position as medical officer on April 3rd I left instructions for the proofs so be sent to me for revision. Dr. E. W. Hope was appointed medical officer on April 4th ; and, instead of the proofs being sent to me as requested, he kept them in his own hands, and I now find, on perusing the published report, that my report has been altered, many portions having been lertt out and extraneous matter introduced, and Dr. Hope announces himself on the title-page as joint compiler, with me, of the report. Surely, Sirs, this is not in accordance with the regulations of the Local Government Board, or with the courtesy one expects from a successor. I have written to the chairman of the Health Committee on the subject without any satisfactory result, and I forward you by this post a copy of the Courier newspaper containing our correspondence. Kindly insert this in your valuable paper.-I am. Sirs, yours faithfully,

$$
\text { J. STOPFORD TAYLOR. M.D., }
$$$$
\text { Grove-park, Lirerpool, Aug. 3rd, } 1894 .
$$

* * The Local Government Board have always held that a medical officer of health, on resignation, ought to be himself responsible for the report on so much of the year's proceedings as were included within the period for which he held office; and on several occasions his successor has written a separate report on the remainder of the year. In this instance the report had apparently to do with a period during which Dr. Stopford Taylor alone held office, and clearly his report and his alone can be regarded as the official one. If the health committee desired modification of the report they should have conferred with Dr. Taylor as to this.
Clearly, no one else had a right to modify it, whatever objection might be regarded as attaching to it. Dr. Taylor will be quite justified in officially disclaiming all responsibility for a document thus altered.-ED. L.

\section{RARE CAUSE OF DEATH IN UTERINE FIBROID. To the Editors of THE LANCET.}

SIRs,-As it is generally stated in text-books, and is held as an opinion by many gynæcologists, that fibroid tumours of the womb are vary rarely the cause of death, it may prove interesting, especially to those who are in the habit of meeting with these cases, to briefly relate one in which a fatal event was attributable to the presence of a growth of this kind.

I was called to see a woman aged forty-two, unmarried, concerning whom I obtained the following history. Three days previously she had suffered from swelling of the left leg, rendering locomotion painful though not impossible. On the morning of the day I saw her she was seized with faintness on rising from bed and felt so ill that she was obliged to remain there. This, with a history of menorrhagia, was all that could be obtained. I found her lying in bed with half closed eyes, extreme pallor of skin, the hands and feet icy cold, the pulse barely perceptible, no cyanosis or sweats, and the respiration rapid, deep, occasionally sighing-in iact, a marked condition of " air-hunger," to use a Teutonic expression, the exhaled air being quite cold. Although she could only speak in a whisper, the mental faculties were perfect, and she complained of a sense of weight and oppression at the epigastrium and a feeling of great distress and faintness; there was also a little retching at times. On examination of the chest there were found no diagnostic signs in the lungs, the air entering fully every where; the heart sounds were almost inaudible. The left leg was cdematous; a group of hard and enlarged veins could be felt on the inner side of the knee. In the abdomen a large central hard tumour was found reaching two fingers' breadths above the umbilicus-it was freely movable, non-fluctuating, and dull on percussion ; it gave no auscultatory signs and presented all the appearance of a uterine fibroid. There was no tenderness over the tumour; the mammæ were virgin. A small quantity of clear normal urine was drawn off by the catheter. Heat was applied to the extremities, with sinapisms to the precordinm. Injections of one-fiftieth of a grain of strychnine and ether were given subcutaneously, and oxygen for inhalation, but these remedies unfortunately proved unavailing, and she died eighteen hours after the first symptom of acute illness. Such a termination of a case where uterine fibroid had caused little inconvenience and had not previously attracted the attention of her usual medical attendant is decidedly rare and deserves notice. The cause of death was evidently the clotting of blood in the heart itself or large bloodvessels, and this was brought about either by thrombosis in the femoral vein and subsequently in the auricle, caused by the anæmia, or, thrombosis of the femoral vein having occurred from pressure of or extension from the tumour, embolism had resulted in the pulmonary artery. I incline to the latter supposition because of the sudden onset which happened on the patient getting out of bed in the morning, a process calculated to detach a soft clot formed during sleep.-. $\mathrm{I}$ am, Sirs, yours faithfully,

Sloane-street, July 31st, $1894 . \quad$ VINCENT DICKINSON.

\section{"AN EPIDEMIC OF SUICIDE." To the Editors of THE LANCET.}

SIRs, - I have been much interested in the note of your Paris correspondent on the above subject, ${ }^{1}$ because I believe that my researches enable me to explain many of the facts he mentions. In the Practitioner of November, 1888, I pointed out the relation of mental depression and suicide to seasonal variations in temperature, drawing special attention to the excess of suicides in France in July, and I have ever since been collecting facts and statistics bearing on the subject. What I suggested was that the relation of mental depression and suicide to temperature was simply its relation to the effects of temperature on urate excretion, for $I$ have shown that excess of uric acid in the blood causes high arterial

$x$ THE LANCET, July 28th, 1894. 
tension, which affects to a very important extent the intracranial circulation. ${ }^{2}$ And when my researches come to be published in full it will, I think, be evident that there is not only a diurnal fluctuation in the excretion of uric acid, with a maximum excretion in the alkaline tide of the morning and a minimum excretion in the acid tide of the evening and early night, but that there is also, for similar reasons, an annual fluctuation in excretion, with a maximum in the warm months (April to July), when the acidity of the urine is at its lowest and the alkalinity of the blood at its highest point, and a minimum in the cold months (November to March), when the urinary acidity is greatest and the alkalinity of the blood least. In the daily cycle the excessive excretion in the morning is, as I have shown, ${ }^{3}$ largely dependent on the retention of the previous evening and night; so in the yearly cycle the excessive excretion in the warm months is largely dependent on the previous retention in the cold months. Your correspondent specially mentions the onset of hot weather, and this is very interesting, because it is just with the onset of the heat and the first great fall in the acidity of the urine that the great rush of stored uric acid into the blood will take place. Then, again, 6 A.M. to 12 noonthe most frequent time for the fatal act-is also just the time of the largest daily excretion of uric acid-i.e., the time when there is most of it passing through the blood-and the facts I have collected will, I think, fully bear out this observation. In contrast with mental depression and suicide, gout shows us the effects of the opposite, or retention, end of the excretion cycles, for as regards the day its temperature is highest and the pain greatest in the evening and night, and lowest, and the pain least, in the hours of the forenoon ; and, as regards the year, Sydenham is very emphatic as to February (towards the end of the retention period) being the month for first or most severe attacks, while he is equally careful to point out that if attacks are absent, or if chronic gout ever relaxes its hold, it is in the warm summer months. As to "lunar development" I have nothing to say, unless the moon is one of the factors in the weather ; but valleys are generally more relaxing (equal plus perspiration lowered, acidity of urine, and increased alkalinity of blood) than elevated regions, even if blood pressure does not rise and fall with atmospheric pressure; and Scotland, as I have elsewhere pointed out, is "the land o' cakes," but not of roast beef, so that diet may to some extent account for the racial differences your correspondent notices. I am, Sirs, yours truly,

Aug. 7th, 1894.

Alexander Haig.

\section{THE NORTHERN WORKHOUSE NURSING ASSOCIATION.}

To the Editors of THE LANCET.

SIRS, - The revelations that have taken place in regard to the treatment of the poor in some of our workhouses must have convinced a great many people that poor Tom Hood's poem containing the line

$$
\text { "He's only a pauper whom nobody owns" }
$$

is too true, not oniy as regards the dead, but unfortunately still more so as regards the living. The public conscience appears to have been aroused, and there is a strong desire that something should be done to make our workhouse infirmaries worthy of being what they really are-the State hospitals of England. The object of the Northern Workhouse Nursing Association is to attain this devoutly to be wished for consummation, and for several years they have been doing their best to improve the nursing in workhouses by providing trained nurses thoroughly acquainted with the duties in a workhouse. It has been found by experience that nurses trained in first-class workhouse hospitals, like Birmingham, Chorlton, Manchester, Marylebone, and several other places, are better suited for the work than those obtained from general hospitals. Already the association has been able to provide twenty-three unions with nurses, and in only one union has there been any friction between the association and the guardians, and in that case we think the public will scarcely blame the association when they know the manner in which the nurses were treated. For instance, the stove upon which the nurses cooked their food was in their bedroom, the paupers' bath-room answered a double purpose, serving as it did as a pantry in which to keep the nurses food, such as it was. The cleanliness of the

2 Brain, 1892 and 1893

3 tric Acid, second edition, p. 14 et seq. institution can be judged from the fact that one nurse was considered extravagant because she wanted the counterpanes in the lying-in ward to be washed at least once in three months on hygienic grounds. Draw sheets were washed in the patients' lavatories and dried at night in the patients day-room. Hot water was only available for the bath-rooms once a week. Not long since a very experienced union clerk expressed the opinion that the greatest impediments to the employment of trained nurses in workhonses are the master and matron. In some of the large workhouses the persons occupying the positions named are ladies and gentlemen, but even then it is only in very rare cases that the matron understands anything about really scientific nursing, and unfortunately they are too often ignorant of their own ignorance, and do very much less than they might do to make the nurses comfortable. It is impossible to imagine a more short-sighted policy on the part of guardians than that of neglecting to make proper provision for the comfort of their officials. I remember Mr. Basil Caine once saying that "it pays the public to make their officials comfortable, because by so doing they attract the best class of officers, and therefore the work is better done." Now, if we are to make our workhouse nurses comfortable it will be necessary to place the government of the sick wards on a basis similar to that in force in Scotland, where the board of supervision require one trained nurse for every twenty cases, and if the number amounts to upwards of sixty a lady superintendent must be appointed in addition, and in these cases the matron has no authority of jurisdiction, and of course no responsibility. If the Local Government Board would issue a similar order the work of the Northern Workhouse Nursing Association would be made much easier in one direction, and it would also be made much easier in another direction if the public would assist us financially. The association is doing its best to assist alike the guardians, nurses, and the sick poor, but funds are needed to carry on the work,

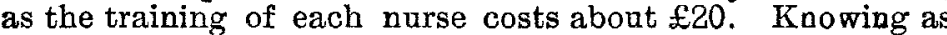
we do the good work that has been accomplished we feel that we have a right to appeal to all sensible people to assist in doing our best to cause these horrible workhouse scandals to be only a sad memory of a melancholy past and not a dreadful reality of the present.

I am, Sirs, yours faithfully, JOHN MILSON RHODES, M.D.

Chairman of the Northern Workhouse Nursing Association. Barton Arcade, Manchester, Aug. 6th, 1894.

\section{"THE NEW MEDICAL DEFENCE ASSOCIA- TION, LIMITED." \\ To the Editors of TH $\mathrm{T} \mathrm{LAN} \mathrm{CET}$.}

SIRS, - In your last issue the secretary of a new medical defence association not only challenges the Medical Defence Union to publish its financial position, bat also denies the truth of your just opinion that the floating of a new company to form a third society of the kind is quite unnecessary, since the present machinery is so very efficient and active. The Medical Defence Union has already in the journals and at the recent annual meeting of the British Medical Association wideiy published its present flourishing financial state, but the council is glad of the opportunity afforded by Mr. Chaldecott's letter to do so once again and as clearly and prominently as possible, the more especially as the facts entirely corroborate your views. We may observe that, as Mr. Chaldecott knows well the answer to his first question is contained in the balance-sheet and financial statement published some six months ago in the Council's Report for 1893. No further notice of this or of his second question, which contains two assertions directly contrary to the fact, is therefore called for. Mr. Chaldecott further is anxious that the world should be informed how much cash the Medical Defence Union has in hand to carry on the work of the remaining four or five montbs of this year. As he declared that his new company to his knowledge possesses more than double the property of the two previously existing societies taken together, he must be able himself to answer his own question. Since, however, your readers may desire to have some true idea of the position of the Union, we may state that the cash in hands amounts to some hundreds of pounds, a sum, in fact, greater than the Union has previously possessed at a corresponding period of the year. The following statement, which was extensively circulated at Bristol last week, and is being sent to every 